\title{
Effect of Metal Cations on Corrosion Behavior and Surface Structure of Carbon Steel in Chloride lon Atmosphere
}

\author{
Yu-Wei Liu, ${ }^{1,2}$ Jian Zhang ${ }^{3} \cdot$ Xiao Lu ${ }^{1,2} \cdot$ Miao-Ran Liu $^{1,4} \cdot$ Zhen-Yao Wang $^{1}$
}

Received: 23 October 2019 / Revised: 26 November 2019 / Published online: 18 July 2020

(c) The Chinese Society for Metals (CSM) and Springer-Verlag GmbH Germany, part of Springer Nature 2020

\begin{abstract}
In order to better understand why the corrosion behavior of carbon steel exposed in Nansha atmospheric environment is very serious, the effect of sodium, potassium and magnesium chlorides deposited on carbon steel surface has been studied under atmosphere conditions by wet/dry accelerated test. The difference of corrosion behavior and surface structure in $\mathrm{Na}^{+}$, $\mathrm{K}^{+}$, and $\mathrm{Mg}^{2+}$ containing atmosphere has been investigated by thickness loss, scanning electron microscope, X-ray diffraction and electrochemical techniques. The results indicate that the thickness loss of carbon steel exposed in different metal cations containing atmospheric environment increases in the order of $\mathrm{Na}^{+}, \mathrm{K}^{+}, \mathrm{Mg}^{2+}$. The hard metal cation can promote the dissolution of the steel to a certain extent. In $\mathrm{Mg}^{2+}$ containing atmosphere, the relative content of $\beta$-FeOOH is rather higher and the protective ability index $\alpha^{*} / \gamma^{*}$ decreases in the order of $\mathrm{Na}^{+}, \mathrm{K}^{+}, \mathrm{Mg}^{2+}$. The corrosion current density of both bare carbon steel and the rusted carbon steel increases in the order of $\mathrm{Na}^{+}, \mathrm{K}^{+}, \mathrm{Mg}^{2+}$. The polarization resistance and the charge transfer resistance decreases in the order of $\mathrm{Na}^{+}, \mathrm{K}^{+}, \mathrm{Mg}^{2+}$.
\end{abstract}

Keywords Metal cation $\cdot$ Carbon steel $\cdot$ Chloride $\cdot$ Atmospheric corrosion

\section{Introduction}

Atmospheric corrosion of carbon steel exposed in open air is usually a serious failure form due to its complex interaction in the presence of multiphase between the material and the surrounding atmospheric environment. Both the metal properties and the absorbed salts influence the corrosion of metal structures. Generally, dense and electrochemical inert rust layers can reduce the corrosion rate [1, 2], whereas in

Available online at https://link.springer.com/journal/40195.

Zhen-Yao Wang

zhywang@imr.ac.cn

1 Environmental Corrosion Center, Institute of Metal Research, Chinese Academy of Sciences, Shenyang 110016, China

2 School of Materials Science and Engineering, University of Science and Technology of China, Shenyang 110016, China

3 Analysis and Testing Center, Institute of Metal Research, Chinese Academy of Sciences, Shenyang 110016, China

4 University of Chinese Academy of Sciences, Beijing 100049, China chlorine-rich marine atmospheres, the protective rust layer cannot form [3-7]. A characteristic corrosion product akaganeite generates on carbon steel, which notably accelerates the corrosion rate and reduces the protective ability of the rust layers [8-10]. The concentration of chloride and sulfate in absorbed salts was often considered as a main influencing factor, while the effect of metal cations on atmospheric corrosion process has been disregarded for a long time. Until recently, many researches have focused on the effect of metal cations on corrosion behavior of aluminum alloy, magnesium, zinc and mild steel. Otani et al. [11] investigated the effect of six different metal cations on the oxide film structure of A3003 aluminum alloy in model tap waters and pointed out that the mass change rate and corrosion current density decreased with increasing metal cation hardness, and $\mathrm{Zn}^{2+}$ and $\mathrm{Ni}^{2+}$ were tend to incorporated in the oxide films. Liu et al. [12] investigated the effect of metal cations on corrosion behavior of $\mathrm{Mg}$, and pointed out that the corrosion rate of $\mathrm{Mg}$ was in the descending order of $\mathrm{Na}^{+}$, $\mathrm{Ca}^{2+}, \mathrm{Mn}^{2+} ; \mathrm{Ca}^{2+}$ and $\mathrm{Mn}^{2+}$ can promote the formation of a more homogeneous and compact corrosion product film on the surface of $\mathrm{Mg}$. Prosek et al. [13] investigated the effect of cations on zinc corrosion and the results showed that the cations strongly affected the corrosion rate of zinc due to 
the formation of hydrozincite, simonkolleite and other complex products. Lindstrom et al. [14] found that compared to $\mathrm{NH}_{4}{ }^{+}, \mathrm{Mg}^{2+}$ and $\mathrm{Zn}^{2+}, \mathrm{Na}^{+}$was by far the most corrosive toward zinc and explained that comparatively rapid corrosion might be caused by the absence of insoluble sodium compounds. Islam et al. [15] investigated the effect of metal cations on mild steel corrosion in chloride aqueous solution and found that metal cation $\mathrm{Zn}^{2+}$ had a significant effect on corrosion inhibition because it was incorporated in the oxide films by making a strong bond. Thus, the metal cations have a great influence on metal corrosion process.

The existing researches mostly focus on corrosion behavior of metal immersed in solution or in tap water, while the study on effect of metal cations on atmospheric corrosion behavior of metal is still less. It is well known that the material used in actual atmosphere is attacked by both anion and cation, and the corrosion rate of metal in complex composition seawater is larger than that in single sodium chloride solution [16]. Also in tropical marine atmospheric environment, the higher content of cations mainly includes $\mathrm{Na}^{+}, \mathrm{K}^{+}$ and $\mathrm{Mg}^{2+}$ [17]. Therefore, the main objective of this study was to compare the effect of different cations $\left(\mathrm{Na}^{+}, \mathrm{K}^{+}\right.$and $\mathrm{Mg}^{2+}$ ) on corrosion behavior of carbon steel in $\mathrm{Cl}^{-}$atmosphere and to understand better the role of cations in corrosion process.

\section{Experimental}

\subsection{Material Preparation and Corrosion Medium}

Low-carbon steel Q235 was chosen as testing material, which contains (in mass\%) 0.22 C, $0.08 \mathrm{Si}, 0.10 \mathrm{Mn}, 0.015$ $\mathrm{P}, 0.003 \mathrm{~S}$ and $\mathrm{Fe}$. The surface sizes of the samples were $50 \mathrm{~mm} \times 25 \mathrm{~mm}, 15 \mathrm{~mm} \times 15 \mathrm{~mm}$ and $10 \mathrm{~mm} \times 10 \mathrm{~mm}$, respectively, for thickness loss measurement, rust layer analysis and electrochemical tests. The samples for thickness loss and rust layer analysis were mechanical polished to Ra 0.8 (the surface roughness). The electrochemical test samples were wet polished with \#240, \#400, \#800 and \#1000 grade $\mathrm{SiC}$ paper. Before accelerated test, all samples were ultrasonically cleaned with acetone, dried and stored prior to use.

The corrosion medium selection was based on seawater composition (Table 1). Seawater was retrieved from the China South Sea. It can be seen that in addition to $\mathrm{Na}^{+}$, the content of $\mathrm{K}^{+}$is relative high. $\mathrm{Mg}^{2+}$ is also a main metal cation that cannot be ignored. Thus, this study focuses on the effect of different metal cations $\left(\mathrm{Na}^{+}, \mathrm{K}^{+}\right.$and $\left.\mathrm{Mg}^{2+}\right)$ on carbon steel corrosion, and the concentration of chloride was uniformly set as $0.6 \mathrm{~mol} / \mathrm{L}$ similar to seawater. Three different salt solutions, $0.6 \mathrm{~mol} / \mathrm{L} \mathrm{NaCl}, 0.6 \mathrm{~mol} / \mathrm{L} \mathrm{KCl}$ and $0.3 \mathrm{~mol} / \mathrm{L} \mathrm{MgCl}$.
Table 1 Main element composition of the seawater (g/L, pH 6.6)

\begin{tabular}{llllll}
\hline $\mathrm{Cl}^{-}$ & $\mathrm{SO}_{4}{ }^{2-}$ & $\mathrm{K}^{+}$ & $\mathrm{Na}^{+}$ & $\mathrm{Ca}^{2+}$ & $\mathrm{Mg}^{2+}$ \\
\hline 20 & 2.18 & 5 & 10 & 0.3 & 1 \\
\hline
\end{tabular}

\subsection{Cyclic Accelerated Corrosion Process}

The corrosion process was tested using Weiss-Voetsch (C4-180) high- and low-humidity test chamber. The cyclic corrosion process included two steps with a period of $24 \mathrm{~h}$ : (1) uniformly depositing $20 \mu \mathrm{L} / \mathrm{cm}^{2}$ corrosion medium $\left(0.6 \mathrm{~mol} / \mathrm{L} \mathrm{NaCl}, 0.6 \mathrm{~mol} / \mathrm{L} \mathrm{KCl}\right.$ and $\left.0.3 \mathrm{~mol} / \mathrm{L} \mathrm{MgCl}_{2}\right)$ on the surface of the samples and then drying in the oven at $35^{\circ} \mathrm{C}$; (2) putting the samples in the chamber and running the program $\left(35^{\circ} \mathrm{C}, 90 \% \mathrm{RH}\right.$ and $35^{\circ} \mathrm{C}, 60 \% \mathrm{RH}$ for $2 \mathrm{~h}$, respectively) six times. Repeat steps (1) and (2) to 10 cycles.

\subsection{Thickness Loss and Rust Layer Analysis}

After pre-treatment and drying, carbon steel samples were weighted to obtain the initial mass $w_{0}$. After $240 \mathrm{~h}$ corrosion, rust was removed by immersing the samples in an aqueous solution of $500 \mathrm{~mL} \mathrm{HCl}, 500 \mathrm{~mL}$ distilled water and $3.5 \mathrm{~g}$ hexamethylenetetramine at approximately $20{ }^{\circ} \mathrm{C}$ for several minutes (dependent on rust amount). After corrosion products were removed, the samples were rinsed with distilled water and alcohol, then dried with compressed air and then weighted the cleaned coupons to obtain the final mass $w_{t}$. Due to the uniform corrosion of carbon steel, the thickness loss is usually used to evaluate the corrosion rate. The thickness loss can be calculated by the following equation:

$D=\frac{10,000\left(w_{t}-w_{0}\right)}{\rho s}$,

where $D$ is the thickness loss $(\mu \mathrm{m}), w_{t}$ is the final mass $(\mathrm{g})$, $w_{0}$ is the initial mass $(\mathrm{g}), \rho$ is the density $\left(7.86 \mathrm{~g} / \mathrm{cm}^{3}\right)$ of the carbon steel and $s$ is the surface area $\left(\mathrm{cm}^{2}\right)$ of the sample.

The morphology of the rusted samples was detected by digital camera (Nikon D70, Japan), scanning electron microscope (SEM, FEI Inspect F50, USA) and threedimensional surface profilometer (Micro XAM, USA). A RigakuD/max 2000PC was used for analysis of phase constituents. The instrument was operated with $\mathrm{Cu} K \alpha$ target at $50 \mathrm{kV}$ and $300 \mathrm{~mA}$ with a range from $10^{\circ}$ to $70^{\circ}$, step $0.02^{\circ}$. The scanning speed was set as $10^{\circ} / \mathrm{min}$ for qualitative analysis and $1 \%$ min for quantitative analysis. 


\subsection{Electrochemical Test}

The electrochemical test was performed with PARSTAT 2273 (Princeton, USA) and traditional three-electrode cell at room temperature. The working electrode was, respectively, the rusted samples and bare metal. The counter electrode and the reference electrode were, respectively, a large platinum and saturated calomel electrode (SCE). The electrolyte was tested solution of different corrosion mediums containing the same corrosive medium as the corresponding atmospheric environment to reduce the influence of other ions. During the testing process, the test samples were immersed in the electrolyte until a stable corrosion potential obtained, then the amplitude of AC voltage was set as $10 \mathrm{mV}$ and the frequency range was from $10^{5} \mathrm{~Hz}$ to $10^{-2} \mathrm{~Hz}$, and the potentiodynamic polarization measurements were carried out at a scanning rate, $20 \mathrm{mV} / \mathrm{min}$ and a scan range, $-0.25 \mathrm{~V}$ relative to the open circuit potential to $0 \mathrm{~V}$. All electrochemical experiments were repeated three times to ensure reasonable repeatability.

\section{Results and Discussion}

\subsection{Thickness Loss of Carbon Steel Exposed to Different Metal Cations Containing Atmosphere}

The thickness loss of carbon steel exposed to different metal cations $\mathrm{Na}^{+}, \mathrm{K}^{+}$and $\mathrm{Mg}^{2+}$ containing atmosphere after $240 \mathrm{~h}$ is shown in Fig. 1. It can be seen that the thickness loss of carbon steel exposed to different atmospheric environments followed in order of $\mathrm{Na}^{+}<\mathrm{K}^{+}<\mathrm{Mg}^{2+}$. That is to say, in chloride-containing atmospheric environment, metal

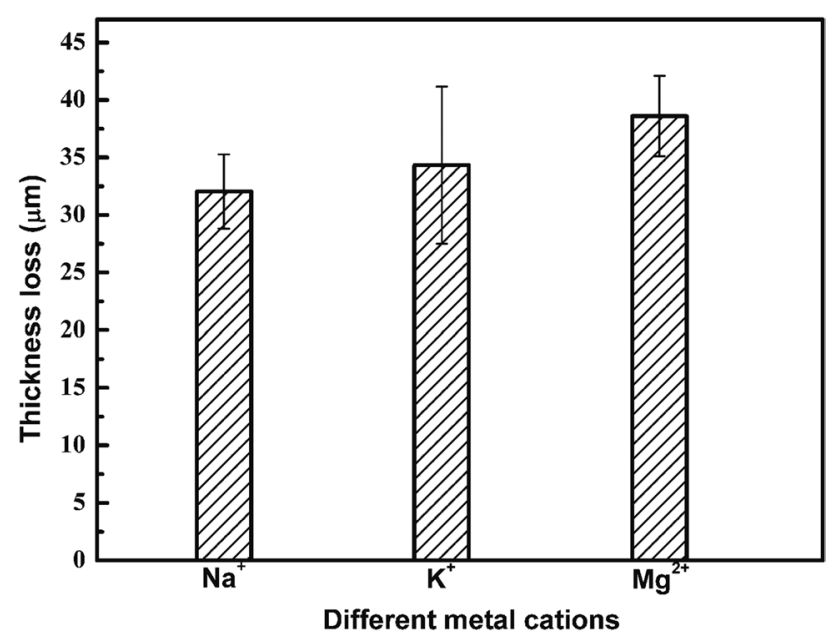

Fig. 1 Thickness loss of carbon steel exposed to different metal cations containing atmosphere after $240 \mathrm{~h}$ cation $\mathrm{Mg}^{2+}$ is much more corrosive to carbon steel than $\mathrm{K}^{+}$and $\mathrm{Na}^{+}$.

Many studies $[11,12,18]$ reported that the corrosion rate of metal is related to the hardness of metal cation in dilute chloride solution. The hardness $(X)$ of metal cations is based on the hard and soft acid-base theory. According to the Lewis theory of acids and bases, the hardness of metal cations can be calculated as follows [11, 19, 20]

$X=\left[X_{\mathrm{M}}^{0}+\left(\sum I_{n}\right)^{\frac{1}{2}}\right]^{2} / 10$,

where $X_{\mathrm{M}}^{0}$ is the electronegativity of the metal atom; $I_{n}(\mathrm{eV})$ is the ionization potential from the neutral metal atom to the given oxidized state; $n$ represents the number of electrons in the valence shell. The relationship between the hardness $(X)$ of metal cations and thickness loss is shown in Fig. 2. It shows that the hardness of $\mathrm{Mg}^{2+}$ is much higher than that of $\mathrm{Na}^{+}$and $\mathrm{K}^{+}$. This suggests that the harder metal cation can promote the dissolution of the steel.

\subsection{Characteristics of the Surface}

In previous study, Zhang et al. [18] investigated the inhibiting effect of metal cations on intergranular stress corrosion cracking (IGSCC) behavior of 304 stainless steel, reflecting that hard metal cations changed the characteristics of passive films to decrease the susceptibility of IGSCC. Thus, we first analyzed the influence of metal cation hardness on carbon steel surface. Surface images of carbon steel exposed in atmospheric environment containing $\mathrm{NaCl}, \mathrm{KCl}$ and $\mathrm{MgCl}_{2}$ after $240 \mathrm{~h}$ are shown in Fig. 3. Left to right, the images are in the order of different metal cations $\mathrm{Na}^{+}$, $\mathrm{K}^{+}$and $\mathrm{Mg}^{2+}$ containing atmosphere. It is clearly seen that

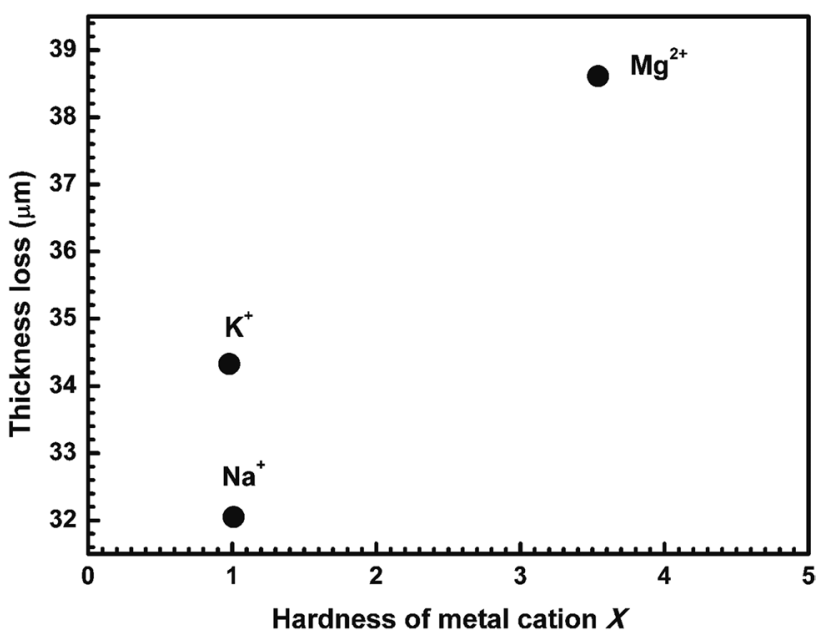

Fig. 2 Changes in average thickness loss of carbon steel as a function of the hardness of the added metal cations 


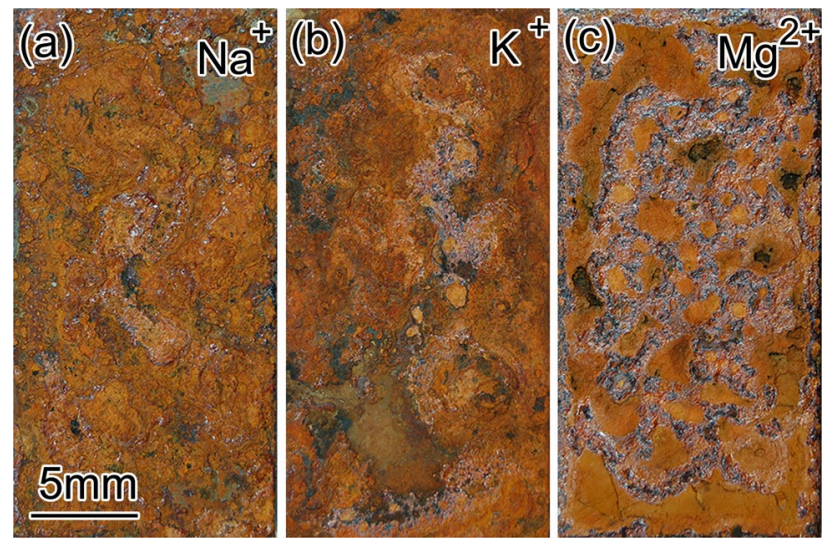

Fig. 3 Macro-morphologies of corrosion products formed on carbon steel exposed to different metal cations containing atmosphere after $240 \mathrm{~h}$
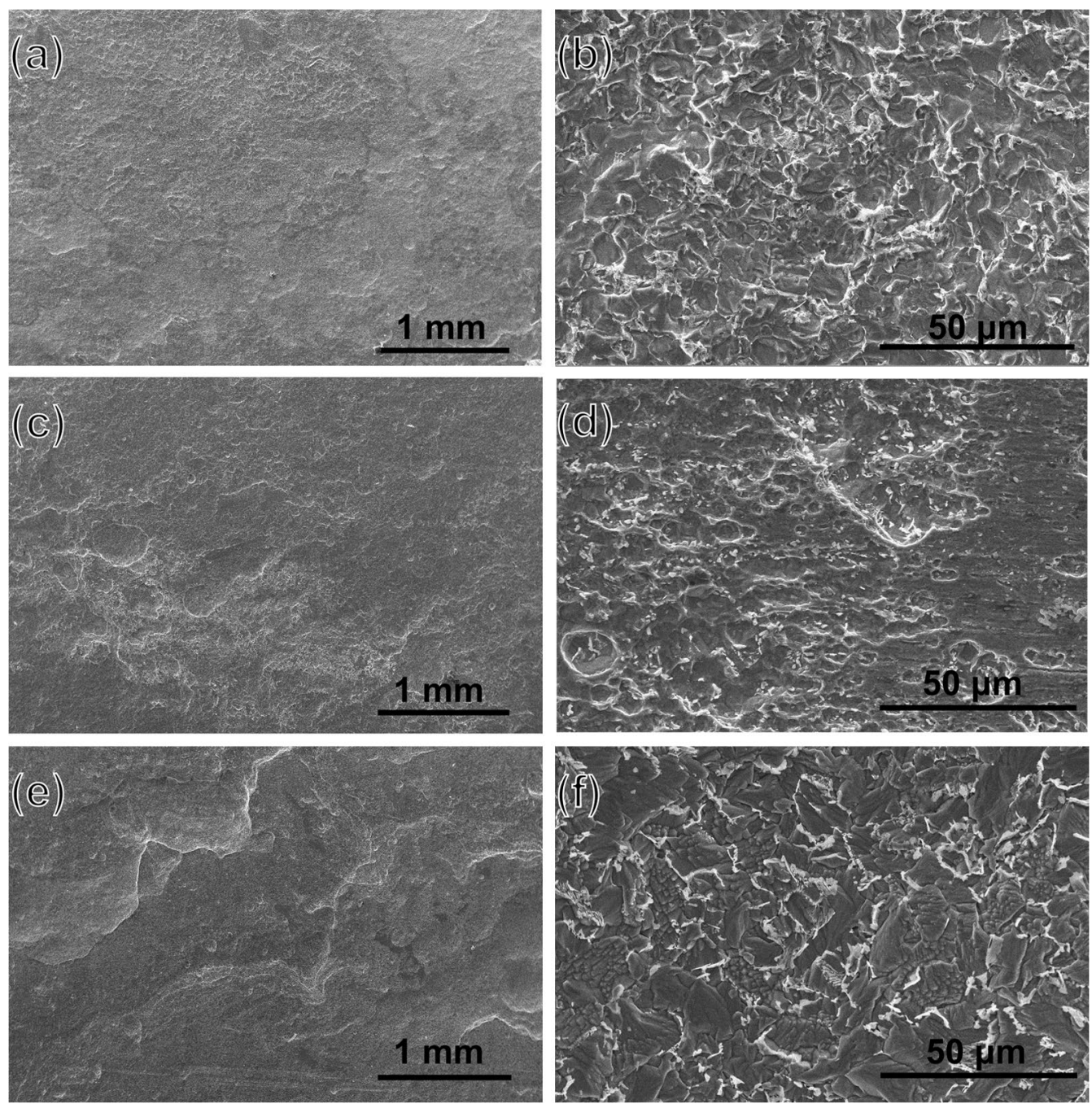

Fig. 4 SEM images of the carbon steel surface after removal of the corrosion products in different metal cations containing atmosphere after $240 \mathrm{~h}$ for $\mathbf{a}, \mathbf{b ~ N a C l} ; \mathbf{c}, \mathbf{d ~ K C l} ; \mathbf{e}, \mathbf{f} \mathrm{MgCl}_{2}$ 

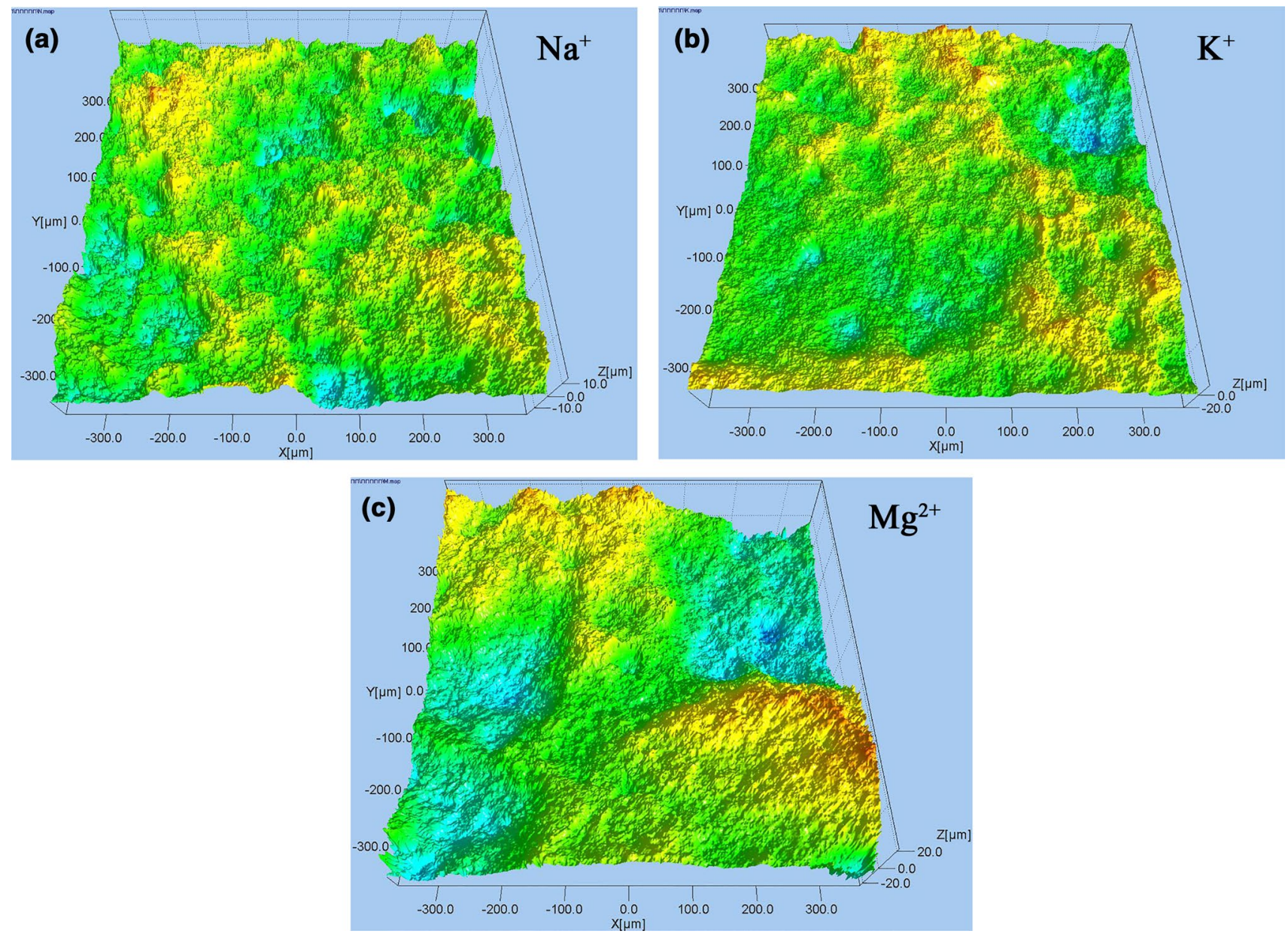

Fig. 5 Three-dimensional roughness of the carbon steel surface after removal of the corrosion products exposed to $\mathrm{Na}^{+} \mathbf{a}, \mathrm{K}^{+} \mathbf{b}, \mathrm{Mg}^{2+} \mathbf{c}$ containing atmosphere

the surface of sample in $\mathrm{K}^{+}$containing atmosphere, while in other two atmospheres no obvious pit appeared. However, from the three-dimensional roughness of the surface characteristics shown in Fig. 5, we can see that there were a few small pits in these three kinds of atmosphere environment, which was mainly due to the effect of $\mathrm{Cl}^{-}$[21]. The surface roughness increased in the order $\mathrm{Na}^{+}<\mathrm{K}^{+}<\mathrm{Mg}^{2+}$, which intuitively reflected the corrosion extent.

\subsection{Composition of the Corrosion Products}

The corrosion products formed on the sample surface shown in Fig. 6 were analyzed by X-ray diffraction (XRD) to determine the composition and the relative content after exposure for $240 \mathrm{~h}$. The result indicated that the corrosion products formed in three metal cations containing atmospheric environment mainly consisted of $\beta$ - $\mathrm{FeOOH}, \alpha-\mathrm{FeOOH}$, $\gamma$-FeOOH and $\mathrm{Fe}_{3} \mathrm{O}_{4}$. In $\mathrm{Na}^{+}$and $\mathrm{K}^{+}$containing atmospheric environment, there was still certain amount of sodium chloride and potassium chloride residue, respectively, shown in
Fig. 6a, whereas in $\mathrm{Mg}^{2+}$ containing atmospheric environment, product associated with magnesium was not detected. The result also indicated that the consumption of $\mathrm{MgCl}_{2}$ was faster than that of the other two corrosive medium under the same test condition. The relative content of each constituent phase was obtained by Maud software fitting shown in Fig. 6b. As the most typical products in chlorine-rich atmosphere environment $[8,9,22]$, the content of $\beta-\mathrm{FeOOH}$ in these three metal cations containing atmosphere was relatively high, especially in $\mathrm{Mg}^{2+}$ containing atmosphere. Due to the fact that $\beta-\mathrm{FeOOH}$ is an electrochemical active phase of the corrosion products [8] and the key factor to influence the protective effect of the rust layer, the higher content of $\beta$ - $\mathrm{FeOOH}$ accelerated the corrosion rate and weakened the protective property of the rust layer $[9,23]$. Therefore, the corrosion rate of carbon steel exposed in $\mathrm{Mg}^{2+}$ containing atmospheric environment is apparently higher than the other two environments.

Compared with $\mathrm{Na}^{+}$containing atmosphere, in $\mathrm{K}^{+}$containing atmosphere, the relative content of $\alpha-\mathrm{FeOOH}$ and 

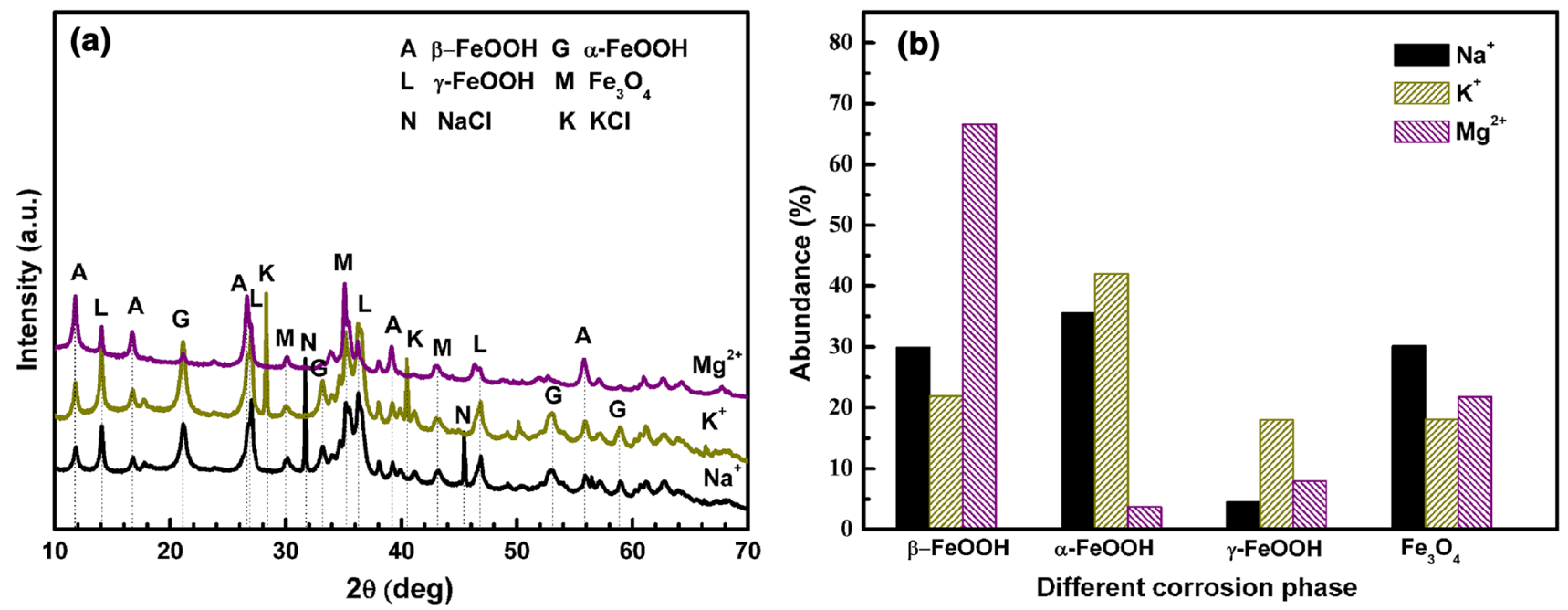

Fig. 6 Composition of corrosion products formed on carbon steel exposed to different metal cations

$\gamma$-FeOOH was both higher. From the perspective of the property of the corrosion product components, $\alpha$-FeOOH is a stable phase, and it is difficult to transform into other products $[24,25] ; \gamma$-FeOOH is a strong reducibility phase, and it is easier to transform into $\alpha$ - $\mathrm{FeOOH}$, or possibility be reduced back to $\mathrm{Fe}_{3} \mathrm{O}_{4}$ [26], or re-crystallized to $\beta$ - $\mathrm{FeOOH}$ [27]; $\mathrm{Fe}_{3} \mathrm{O}_{4}$ is relative stable phase, and it can be formed by interaction of $\gamma$ - $\mathrm{FeOOH}$ and $\beta-\mathrm{FeOOH}$ with iron.

Thus, a further discussion is needed to be clarified through comparing the protective ability index $\alpha^{*} / \gamma^{*}$ [28].

$\alpha^{*} / \gamma^{*}=\left(\alpha+\mathrm{Fe}_{3} \mathrm{O}_{4}\right) /(\gamma+\beta)$.

The ratio $\alpha^{*} / \gamma^{*}$ of carbon steel exposed in $\mathrm{Na}^{+}$and $\mathrm{K}^{+}$containing atmospheric environment is, respectively, 1.905 and
1.503 , indicating a lower protective rust layer formed in $\mathrm{K}^{+}$ containing atmosphere, which may be the cause of higher corrosion rate.

\subsection{Electrochemical Measurement}

Figure 7 shows the anodic and cathodic polarization curves of carbon steel in electrolyte $0.6 \mathrm{~mol} / \mathrm{L} \mathrm{NaCl}, 0.6 \mathrm{~mol} / \mathrm{L}$ $\mathrm{KCl}$ and $0.3 \mathrm{~mol} / \mathrm{L} \mathrm{MgCl}_{2}$ before exposure and after $240 \mathrm{~h}$ exposure. From the polarization curves shown in Fig. 7a, it is found that the corrosion current density in $\mathrm{Mg}^{2+}$ is larger as compared to the other two, and the corrosion current density in $\mathrm{Na}^{+}$is the smallest both in cathodic and anodic polarization curves, while from the polarization curves after $240 \mathrm{~h}$ exposure, the cathodic current density
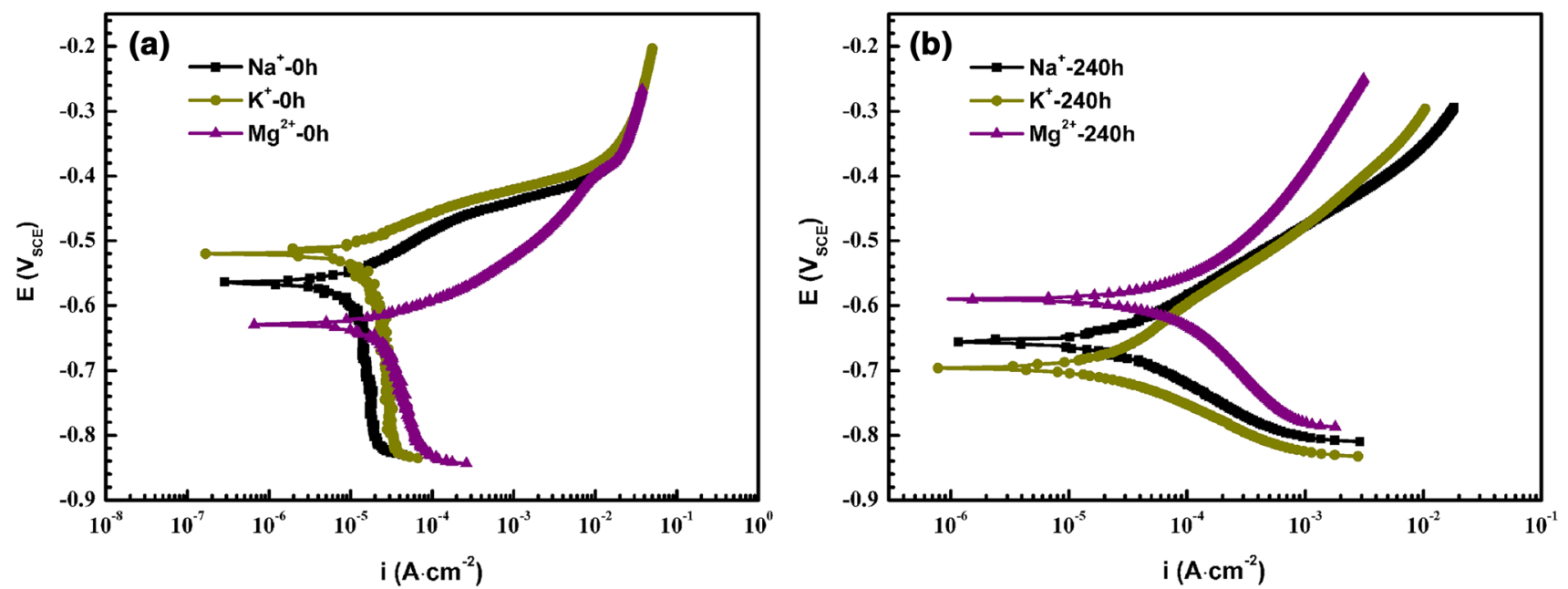

Fig. 7 Potentiodynamic polarization curves of carbon steel in electrolyte with various metal cations for a bare steel; $\mathbf{b}$ rusted steel 
seems larger and the anodic current density seems smaller. For the rusted samples, the cathodic process was mainly controlled by the charge transfer owing to the reduction of ferric rust [9, 29], and the anodic process was controlled by iron dissolution. Thus, polarization curve of rusted layer in $\mathrm{Mg}^{2+}$ may be caused by a faster reaction between rust layer intermediates and a lower rate of iron dissolution. The corrosion current calculated by Tafel extrapolation was, respectively, $15.05 \mu \mathrm{A} \mathrm{cm}^{-2}\left(\mathrm{Na}^{+}\right), 24.53 \mu \mathrm{A} \mathrm{cm}^{-2}\left(\mathrm{~K}^{+}\right)$and $30.81 \mu \mathrm{A} \mathrm{cm}^{-2}\left(\mathrm{Mg}^{2+}\right)$, reflecting a slight increasing trend, while in the research of Otani et al. [11, 12], the corrosion current of A3003 and magnesium decreases with increasing metal cation hardness. The opposite trend of corrosion current reflects differences of the effect of metal cation hardness on different metal corrosion behaviors.

Therefore, the carbon steel electrochemical reaction processes in different metal cations still need further analysis. Electrochemical Impedance Spectroscopy (EIS) measurement was carried out to elucidate the bare and rusted steel corrosion behavior of the carbon steel and the effect of metal cations on the properties of the carbon steel. Figure 8 shows the Nyquist plots and the Bode diagram for bare steel (a, b) and rusted steel (c, d) after $240 \mathrm{~h}$ exposure The Nyquist plots exhibited the same shape before exposure to atmosphere containing different metal cations shown in Fig. 8a, and after $240 \mathrm{~h}$ exposure the Nyquist plot of rusted steel in $\mathrm{Mg}^{2+}$ containing atmosphere changed, showing two time constants. The polarization resistance $R_{\mathrm{p}}$ can be calculated by the following equation [30-32].

$R_{\mathrm{p}}=\left|Z_{\mathrm{L}}\right|-\left|Z_{\mathrm{H}}\right|$,

where $Z_{\mathrm{L}}$ and $Z_{\mathrm{H}}$ is the impedance obtained at low frequency, $10 \mathrm{mHz}$ and high frequency, $10 \mathrm{kHz}$. As shown in Fig. $8 \mathrm{~b}, \mathrm{~d}, R_{\mathrm{p}}$ is in order of $\mathrm{Na}^{+}-0 \mathrm{~h}>\mathrm{K}^{+}-0 \mathrm{~h}>\mathrm{Mg}^{2+}-0 \mathrm{~h}$, $\mathrm{Na}^{+}-240 \mathrm{~h}>\mathrm{K}^{+}-240 \mathrm{~h}>\mathrm{Mg}^{2+}-240 \mathrm{~h}$. It is known that the polarization resistance $R_{\mathrm{p}}$ is inversely proportional to the corrosion rate. Thus, according to the test results, the corrosion rate is inverse to the order of $R_{\mathrm{p}}$. This is consistent with the results of thickness loss. Carbon steel suffered more serious corrosion in the $\mathrm{Mg}^{2+}$ containing atmosphere environment at the same exposure time.
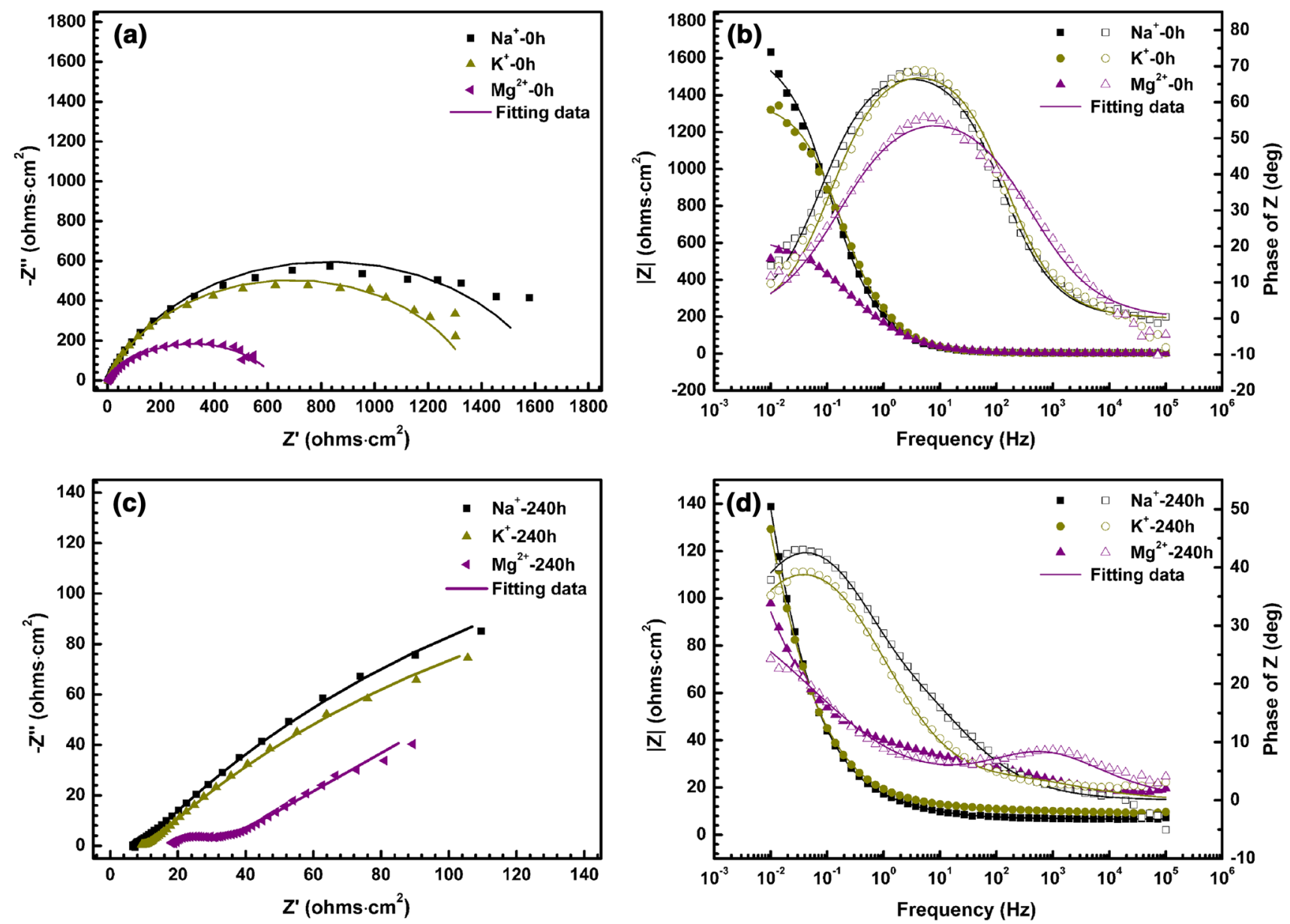

Fig. 8 Nyquist and Bode plots of bare and rusted carbon steel exposed to different metal cations for $\mathbf{a}, \mathbf{b}$ bare steel; $\mathbf{c}, \mathbf{d}$ rusted steel 
(a)
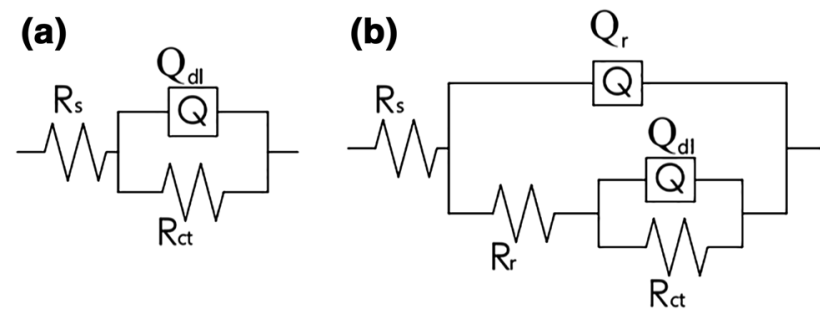

Fig. 9 Equivalent circuits used to fit the experimental EIS data for a rusted carbon steel in $\mathrm{Na}^{+}$and $\mathrm{K}^{+}$containing atmosphere and bare carbon steel; b rusted carbon steel exposed in $\mathrm{Mg}^{2+}$ containing atmosphere

In order to analyze the effect of corrosion products layer in detail, equivalent circuits shown in Fig. 9 are used to fit EIS results. Figure $9 \mathrm{a}$ is for rusted carbon steel in $\mathrm{Na}^{+}$and $\mathrm{K}^{+}$containing atmosphere and bare carbon steel, and Fig. 9b is for rusted carbon steel exposed in $\mathrm{Mg}^{2+}$ containing atmosphere. The fitting data is shown in Fig. 8 as solid line, and the experimental data is shown as scattered points. $R_{\mathrm{s}}, R_{\mathrm{r}}$ and $R_{\mathrm{ct}}$ are, respectively, electrolyte resistance, rust layer resistance and charge transfer resistance; $Q_{\mathrm{r}}$ and $Q_{\mathrm{dl}}$ are, respectively, rust capacitance and electrical double-layer capacitance. All these fitting parameters and the Chi-square values are listed in Table 2. $R_{\mathrm{ct}}$ reflects the inhibition of charge transfer process. The $R_{\mathrm{ct}}$ of bare carbon steel and rusted carbon steel in different metal cations was, respectively, in order of $\mathrm{Na}^{+}-0 \mathrm{~h}>\mathrm{K}^{+}-0 \mathrm{~h}>\mathrm{Mg}^{2+}-0 \mathrm{~h}, \mathrm{Na}^{+}-240 \mathrm{~h}>\mathrm{K}^{+}$$240 \mathrm{~h}>\mathrm{Mg}^{2+}-240 \mathrm{~h}$, indicating that the worst hinder ability of the rust layer formed in $\mathrm{Mg}^{2+}$ to forbid the corrosive ions to react with the substrate.

\subsection{Corrosion Mechanism}

The corrosion reaction of carbon steel in atmosphere is an electrochemical reaction under a thin liquid film. When the relative humidity in the environment is higher than critical relative humidity (RH) (nearly 75\% RH), an electrolyte film can form on the surface of carbon steel, then the electrochemical corrosion process begins. But when some corrosive medium deposits on carbon steel surface, corrosion occurs at rather lower relative humidity. For deposition of sodium chloride and magnesium chloride on carbon steel surface, that corrosion can initiate by adsorbed water at as low as minimum $33 \% \mathrm{RH}$ and $11 \%$ $\mathrm{RH}[16,33]$. Thus, the total time of wetness is higher and absorption of water vapor by salts is often identified as the primary reason of increased corrosivity of metals with salt deposits in contact with atmosphere. Once the water vapor molecules accumulate on the surface, electrochemical reaction occurs.

Anodic reaction: $\mathrm{Fe} \rightarrow \mathrm{Fe}^{2+}+2 \mathrm{e}$

Cathodic reaction: $\mathrm{O}_{2}(\mathrm{~g})+2 \mathrm{H}_{2} \mathrm{O}+4 \mathrm{e} \rightarrow 4 \mathrm{OH}^{-}(\mathrm{aq})$

$$
\mathrm{Fe}^{2+}+2 \mathrm{OH}^{-} \rightarrow \mathrm{Fe}(\mathrm{OH})_{2},
$$

when a continuous thin liquid film forms, $\mathrm{Fe}(\mathrm{OH})_{2}$ is rapidly oxidized to $\mathrm{FeOOH}$ by $\mathrm{O}_{2}$ dissolved in thin liquid film: $2 \mathrm{Fe}(\mathrm{OH})_{2}+1 / 2 \mathrm{O}_{2} \rightarrow \mathrm{FeOOH}+\mathrm{H}_{2} \mathrm{O}$.

There are four types of $\mathrm{FeOOH}$, and the generation and content of each phase is closely related to the reaction process and atmospheric environment. $\gamma$ - $\mathrm{FeOOH}$ is usually a priority generated phase [34], whereas in marine atmosphere, the high amount existence of $\mathrm{Cl}^{-}$is conductive to the formation of $\beta-\mathrm{FeOOH}$, thus the content of $\beta-\mathrm{FeOOH}$ in these three metal cations containing atmosphere was relatively high $(>20 \%)$. During formation process of $\beta$ - $\mathrm{FeOOH}$, a series of intermediate products will produce such as GR I and GR II. As the alternating wet/dry cycle proceeded, many electrochemical unstable phases would be reduced to other intermediates.

In $\mathrm{Mg}^{2+}$ containing atmosphere, as the wet/dry cycle proceeded, many electrochemically unstable phases $(\gamma-\mathrm{FeOOH}$ and $\beta-\mathrm{FeOOH})$ would be reduced to intermediates in wetting stage; magnesium cations may substitute those ferrous ions in the intermediates to form $\mathrm{Mg}$ containing intermediates; then some of these intermediates were oxidized back to $\gamma-\mathrm{FeOOH}$ or transformed to $\mathrm{Fe}_{3} \mathrm{O}_{4}$ in next drying stage [35]. In our study, magnesium compound was not detected, which did not indicate that it had no effect on the corrosion process, but on the contrary, it still played an important role in promoting the electrochemical reactions.
Table 2 EIS fitting parameters for bare and rusted carbon steel in different metal cations

\begin{tabular}{lllllll}
\hline & $\mathrm{Na}^{+}-0 \mathrm{~h}$ & $\mathrm{~K}^{+}-0 \mathrm{~h}$ & $\mathrm{Mg}^{2+}-0 \mathrm{~h}$ & $\mathrm{Na}^{+}-240 \mathrm{~h}$ & $\mathrm{~K}^{+}-240 \mathrm{~h}$ & $\mathrm{Mg}^{2+}-240 \mathrm{~h}$ \\
\hline$R_{\mathrm{s}}\left(\Omega \mathrm{cm}^{2}\right)$ & 4.37 & 4.35 & 3.43 & 6.83 & 9.87 & 16.47 \\
$Q_{\mathrm{r}}\left(\mathrm{F} \mathrm{cm}^{-2}\right)$ & - & - & - & - & - & $1.81 \mathrm{E}-3$ \\
$n_{\mathrm{r}}$ & - & - & - & - & - & 0.45 \\
$R_{\mathrm{r}}\left(\Omega \mathrm{cm}^{2}\right)$ & - & - & - & - & - & 19.08 \\
$Q_{\mathrm{dl}}\left(\mathrm{F} \mathrm{cm}^{-2}\right)$ & $1.09 \mathrm{E}-3$ & $9.04 \mathrm{E}-4$ & $1.53 \mathrm{E}-3$ & $3.14 \mathrm{E}-2$ & $3.26 \mathrm{E}-2$ & $4.85 \mathrm{E}-2$ \\
$n_{\mathrm{dl}}$ & 0.80 & 0.81 & 0.67 & 0.52 & 0.52 & 0.48 \\
$R_{\mathrm{t}}\left(\Omega \mathrm{cm}^{2}\right)$ & 1645 & 1368 & 633.5 & 2210 & 989.3 & 392.8 \\
$\sum \chi^{2}\left(\times 10^{-4}\right)$ & 2.39 & 3.58 & 4.55 & 1.38 & 1.96 & 0.18 \\
\hline
\end{tabular}


In addition, the bivalent magnesium salts is likely hydrolyzed, leading to the drop of $\mathrm{pH}$ at the steel surface, which has a negative effect on the corrosion of carbon steel. In $\mathrm{Na}^{+}$ and $\mathrm{K}^{+}$containing atmosphere, free sodium and potassium ions neither participate in the reaction nor have effect on the $\mathrm{pH}$ of the thin liquid film during the electrochemical reaction process. Consequently, in these two kinds of atmospheric environment, the corrosion rate is relatively slower than that in $\mathrm{Mg}^{2+}$ containing atmosphere. Although the nature of sodium and potassium are extremely similar, the corrosion rate of carbon steel in $\mathrm{K}^{+}$containing atmosphere is larger. Different corrosion rates can be reflected on different compositions of corrosion product, characteristics of the surface and electrochemical properties, but more detailed mechanism still needs further exploration.

\section{Conclusions}

The effect of metal cations on corrosion behavior and surface structure of carbon steel in chloride ion atmosphere was investigated, and the following conclusions may be drawn:

1. The thickness loss of carbon steel exposed in different metal cations containing atmospheric environment followed in order of $\mathrm{Na}^{+}<\mathrm{K}^{+}<\mathrm{Mg}^{2+}$. The hard metal cation $\mathrm{Mg}^{2+}$ can promote the dissolution of the steel.

2. In $\mathrm{Mg}^{2+}$ containing atmosphere, the relative content of $\beta$-FeOOH was rather higher and the protective ability index $\alpha^{*} / \gamma^{*}$ followed in order of $\mathrm{Na}^{+}>\mathrm{K}^{+}>\mathrm{Mg}^{2+}$.

3. The corrosion current density of both bare carbon steel and the rusted carbon steel increased in the order of $\mathrm{Na}^{+}<\mathrm{K}^{+}<\mathrm{Mg}^{2+}$. The polarization resistance $R_{\mathrm{p}}$ and the charge transfer resistance $R_{\mathrm{ct}}$ decreased in the order of $\mathrm{Na}^{+}>\mathrm{K}^{+}>\mathrm{Mg}^{2+}$.

Acknowledgements This work was supported by the National Natural Science Foundation of China (No. 51671197) and the Strategic Priority Research Program of the Chinese Academy of Sciences XDA (No. 13040502)

\section{References}

[1] M. Stratmann, K. Bohnenkamp, H.-J. Engell, Corros. Sci. 969, 23 (1983)

[2] D. de la Fuente, I. Díaz, J. Simancas, B. Chico, M. Morcillo, Corros. Sci. 604, 53 (2011)
[3] S. Hara, T. Kamimura, H. Miyuki, M. Yamashita, Corros. Sci. 1131, 49 (2007)

[4] M. Morcillo, B. Chico, D. de la Fuente, J. Alcántara, I. Odnevall Wallinder, C. Leygraf, J. Electrochem. Soc. 8, 164 (2016)

[5] M. Morcillo, B. Chico, J. Alcántara, I. Díaz, R. Wolthuis, D. de la Fuente, J. Electrochem. Soc. C426, 163 (2016)

[6] D. de la Fuente, I. Díaz, J. Alcántara, B. Chico, J. Simancas, I. Llorente, A. García-Delgado, J.A. Jiménez, P. Adeva, M. Morcillo, Mater. Corros. 227, 67 (2016)

[7] D.H. Xia, C. Ma, Y. Behnamian, S.S. Ao, S.Z. Song, L.K. Xu, Measuremeat 106946, 148 (2019)

[8] T. Kamimura, S. Hara, H. Miyuki, M. Yamashita, H. Uchida, Corros. Sci. 2799, 48 (2006)

[9] T. Nishimura, H. Katayama, K. Noda, T. Kodama, Corrosion 935, $56(2000)$

[10] Y.T. Ma, Y. Li, F.H. Wang, Corros. Sci. 997, 51 (2009)

[11] K. Otani, M. Sakairi, R. Sasaki, A. Kaneko, Y. Seki, D. Nagasawa, J. Solid State Electrochem. 325, 18 (2013)

[12] X.D. Liu, Y.D. Wang, M. Yan, Y.H. Wei, L.F. Hou, C.L. Guo, J. Taiyuan Univ. Technol. 676, 49 (2018). (in Chinese)

[13] T. Prosek, D. Thierry, C. Taxén, J. Maixner, Corros. Sci. 2676, 49 (2007)

[14] R. Lindström, J.-E. Svensson, L.G. Johansson, J. Electrochem. Soc. B57, 149 (2002)

[15] M. Saiful Islam, K. Otani, M. Sakairi, Corros. Sci. 17, 131 (2018)

[16] E. Schindelholz, B.E. Risteen, R.G. Kelly, J. Electrochem. Soc. C460, 161 (2014)

[17] Y.W. Liu, J. Zhang, Y.H. Wei, Z.Y. Wang, Mater. Chem. Phys. 121855, 237 (2019)

[18] S.H. Zhang, T. Shibata, T. Haruna, Corros. Sci. 1049, 47 (2005)

[19] W. Gordy, W.J. Orville Thomas, J. Chem. Phys. 439, 24 (1956)

[20] M. Misono, E.I. Ochiai, Y. Saito, Y. Yoneda, J. Inorg. Nucl. Chem. 2685, 29 (1967)

[21] R.T. Foley, Corrosion 58, 26 (1970)

[22] M. Yamashita, H. Konishi, T. Kozakura, J. Mizuki, H. Uchida, Corros. Sci. 2492, 47 (2005)

[23] Y.T. Ma, Y. Li, F.H. Wang, Mater. Chem. Phys. 844, 112 (2008)

[24] Z.F. Wang, J.R. Liu, L.X. Wu, R.D. Han, Y.Q. Sun, Corros. Sci. 1, 67 (2013)

[25] M. Morcillo, J.M. González-Calbet, J.A. Jiménez, I. Díaz, J. Alcántara, B. Chico, A. Mazarío-Fernández, A. Gómez-Herrero, I. Llorente, D. de la Fuente, Corrosion 872, 71 (2015)

[26] Y.Y. Chen, H.J. Tzeng, L.I. Wei, L.H. Wang, J.C. Oung, H.C. Shih, Corros. Sci. 1001, 47 (2005)

[27] T. Misawa, K. Hashimoto, S. Shimodaira, Corros. Sci. 131, 14 (1974)

[28] P. Dillmann, F. Mazaudier, S. Hœrlé, Corros. Sci. 1401, 46 (2004)

[29] I. Matsushima, T. Ueno, Corros. Sci. 129, 11 (1971)

[30] S.C. Chung, S.L. Sung, C.C. Hsien, H.C. Shih, J. Appl. Electrochem. 607, 30 (2000)

[31] Y.Y. Chen, S.C. Chung, H.C. Shih, Corros. Sci. 3547, 48 (2006)

[32] Y.J. Liu, Z.Y. Wang, W. Ke, Corros. Sci. 169, 80 (2014)

[33] E. Schindelholz, B.E. Risteen, R.G. Kelly, J. Electrochem. Soc. C450, 161 (2014)

[34] T. Misawa, K. Asami, K. Hashimoto, S. Shimodaira, Corros. Sci. 279, 14 (1974)

[35] J. Wang, Z.Y. Wang, W. Ke, Mater. Chem. Phys. 952, 124 (2010) 